\title{
Development Plan for the Territories in the Far North of the Krasnoyarsk Krai for 1977-1990
}

\author{
Sergei T. Gaidin*a, Galina A. Burmakinaa, \\ Tatiana G. Sheremetova and Ruslan V. Pavlyukevicha, \\ ${ }^{a}$ Krasnoyarsk State Agrarian University \\ Krasnoyarsk, Russian Federation \\ ${ }^{b}$ Siberian Federal University, \\ Krasnoyarsk, Russian Federation
}

Received 30.09.2021, received in revised form 25.10.2021, accepted 10.11.2021

\begin{abstract}
This article analyses the background, origins and elaboration of the Extreme North development plan 1977-1990. This plan was another attempt by the Soviet state to elaborate a programme for the development of the Far North territories, involving local, indigenous peoples in economic activities. Such an attempt had first been made under Nikita Khrushchev, but it was eventually abandoned due to the reform of industrial and construction management in 1957. In the late 1970s, with the changed foreign trade balance in the country, the need to develop the northern territories, integrating the indigenous population into the existing economic processes, arose. The state wanted to ensure that the traditional rural economy of the indigenous peoples of the North could reach the level of an industrial society. To this end, a new plan was drawn up. However, no indigenous people participated in the drafting process. The plan embodied the main characteristics of Soviet management: agency, planning and centralism. It envisaged an extensive modernization of all aspects of society in these areas. Its implementation was prevented by the reforms of 1980s and the following break-up of the USSR.
\end{abstract}

Keywords: Siberian north, planned economy, Kraiplan, Gosplan, indigenous peoples of the North, departmentalism, Krasnoyarsk Krai.

This article was written based on the results of the project "The role of the state planning authorities in the socio-economic development of Krasnoyarsk Krai Management in social and economic development of Krasnoyarsk region (economic and Historical Aspect)" No. 2020020605932, supported by the Krasnoyarsk Regional Scientific and Scientific-Technical Activity Support Fund.

Research area: economics.

(C) Siberian Federal University. All rights reserved

* Corresponding author E-mail address: gaydinsergey@rambler.ru ORCID: 0000-0002-1479-5751 (Gaidin), 0000-0003-4916-0745 (Burmakina), 0000-0002-6266-9442 (Sheremetova), 00000003-3537-7118 (Pavlyukevich) 
Citation: Gaidin, S.T., Burmakina, G.A., Sheremetova, T.G. (2021). A Development plan for the territories in the Far North of the Krasnoyarsk krai for 1977-1990. J. Sib. Fed. Univ. Humanit. soc. sci., 14(12), 1840-1850. DOI: 10.17516/1997-1370-0863

\title{
Особенности развития территорий Крайнего Севера Красноярского края в 1977-1990 гг.
}

\author{
С.Т. Гайдин ${ }^{\text {, }}$ Г.А. Бурмакина \\ Т.Г. Шереметова, Р.В. Павлюкевича, \\ аррасноярский государственный аграрный университет \\ Российская Федерачия, Красноярск \\ ${ }^{\sigma}$ Сибирский федеральный университет \\ Российская Федерачия, Красноярск
}

\begin{abstract}
Аннотация. В статье анализируются предпосылки и разработка плана развития территорий, относившихся к Крайнему Северу Красноярского края на 19771990 гг. Подобная попытка уже предпринималась в начальный период хрущевских преобразований, но ее реализация была прекращена в 1957 г. после начала реформы управления промышленностью и строительством в СССР. В связи с изменением внешнеторгового баланса страны в конце 70-х гг. ХХ в. вновь возникланеобходимость развития северных территорий. Разработанный на уровне руководства страны документ был построен на принципах планового развития единого хозяйственного комплекса страны, определения роли конкретных территорий в общесоюзном разделении труда, ответственности министерств и ведомств за его претворение в жизнь. Но начало политики «перестройки» привело к фактическому отказу от его практической реализации.
\end{abstract}

Ключевые слова: Север Сибири, плановая экономика, крайплан, Госплан, коренные народы Севера, ведомственность, Красноярский край.

Статья написана по результатам проекта «Роль плановых органов государственного управления в социально-экономическом развитии Красноярского края (экономикоисторический аспект)» № 2020020605932, поддержанного Красноярским краевым фондом поддержки научной и научно-технической деятельности.

Научная специальность: 08.00.00 - экономические науки.

\section{Введение в проблему исследования}

Северные территории России, и Красноярского края в частности, всегда имели большое значение для экономики страны. Здесь были сосредоточены колоссальные запасы разнообразных полезных ископаемых, огромные лесные массивы, значительные возможности для добычи пушнины, морского зверя и ценных пород рыб.
С первых лет существования советской власти государство рассматривало развитие северных территорий с учетом традиционной специализации хозяйственной деятельности местного населения. Изучение советского опыта хозяйственного освоения региона может быть полезным для выработки модели его развития в современных условиях, что приобретает особую актуаль- 
ность при расширении перевозок по Северному морскому пути.

В современной исторической науке существует высокий интерес к хозяйственному освоению территорий Крайнего Севера Сибири. Следует отметить специалистов Сибирского федерального университета, где данная проблема рассматривается культурологами, экономистами, социологами и историками. Особо хотелось бы выделить работы А.П. Дворецкой (Dvoretskaya, 2021), В.Г. Седельникова (Dvoretskaya, Sedelnikov, 2020), в которых был сделан анализ советской национальной политики на Енисейском Севере в довоенный период. Активно развивается данное направление исследований в рамках Сургутской исторической школы. Здесь следует отметить работы Е.И. Гололобова, который проанализировал моделирование образа региона Сибирского Севера учеными, специалистами, управленцами, связанными с этим регионом как с интеллектуальным конструктом (Gololobov, 2017). Исследователь Ю.С. Михеева рассмотрела проблемы хозяйственного освоения региона с позиции экологии (Mikhheeva, 2017). В работах С.И. Веселова выявлены аспекты транспортного освоения данных территорий во второй половине XX в. (Veselov, 2017). Активно разрабатывает тематику хозяйственного освоения и урбанизации северных территорий с позиции отраслевого подхода И.Н. Стась (Stas, 2017). Но работы, посвященные роли плановых органов в освоении и хозяйственном развитии территорий проживания коренных народов Енисейского Севера, в историографии пока отсутствуют. Анализ исследований сибирских историков позволяет предположить, что большинство из них не знают о плане развития территорий Крайнего Севера Красноярского края на 1977-1990 гг. Исходя из этого авторами статьи была поставлена задача изучить обстоятельства разработки данного плана, его содержание, а также влияние на развитие региона.

\section{Источники и методы исследования}

В основу исследования была положеHa теория модернизации, разработанная британским историком-марксистом Эриком Хобсбаумом (Hobsbawm, 1994), в рамках которой принято считать, что переход советского общества к индустриальной стадии развития имел мобилизационный, догоняющий характер. На разных этапах существования СССР государство ставило новые задачи изменения образа жизни и хозяйственной деятельности коренных малочисленных народов и вовлечения их в процесс построения социализма.

Источниковой базой исследования выступают впервые вводимые в научный оборот материалы Красноярской краевой плановой комиссии, хранящиеся в Государственном архиве Красноярского края (ГАКК).

\section{Обсуждение}

Первые попытки индустриального освоения территорий Енисейского Севера были предприняты в годы проведения индустриализации всей страны. Они были связаны с освоением Норильского месторождения полиметаллических руд и строительством Норильского горнометаллургического комбината. Освоение региона в этот период имело точечный характер, производилось на принципах жесткой мобилизации материальных и человеческих ресурсов. Центральное место в нем играли плановые органы, а за выполнение планов отвечали режимные организации.

Это позволило ценой грандиозных затрат человеческих и материальных ресурсов создать мощную промышленную базу, не имеющую аналогов в мире. Хотя предприятия Норильского промышленного комплекса на первых порах были нерентабельными, они имели стратегическое значение для страны в экономическом и оборонном отношении.

Особую роль в индустриальном освоении природных ресурсов Крайнего Севера играли исправительно-трудовые лагеря системы ГУЛАГ. Коренное население региона сохраняло в тот период традиционный образ жизни и хозяйственной деятельности и практически не участвовало в промышленном производстве. В годы Великой Отечественной войны, когда 
немецко-фашистскими войсками была оккупирована значительная часть сельскохозяйственных территорий европейской части страны, оно было мобилизовано на восполнение продовольственных ресурсов страны за счет вылова рыбы в северных водоемах. Основными отраслями их хозяйственной деятельности в послевоенное время являлись охота, рыболовство и клеточное звероводство.

В марте 1957 г. ЦК КПСС и Совет Министров СССР приняли постановление № 300 «О мерах по дальнейшему развитию экономики и культуры народностей Севера», в котором указывалось, что советская власть многое сделала для коренных малочисленных народов Крайнего Севера, обреченных прежде на вымирание, но министерства и ведомства недостаточно использовали созданную за Полярным кругом мощную производственную базу для их экономического, социального и культурного развития. Постановление требовало от всех организаций и предприятий, работающих на северных территориях, содействовать промышленному и сельскохозяйственному освоению северных территорий и решению социальных проблем коренного населения. Ответственность за выполнение постановления ЦК КПСС и Совет Министров СССР возложили на плановые органы, министерства и ведомства СССР и РСФСР 1 .

Как справедливо отметила историк В.А. Тураева, данное постановление представляло собой комплексную программу развития территорий проживания коренных малочисленных народов Севера (Turaeva, 2014:132). Но начатый через несколько месяцев перевод страны на территориальную систему управления промышленностью и строительством создал проблемы для его практической реализации, привел к ликвидации большинства министерств и ведомств, а комплексное решение проблем малочисленных коренных народов не входило в перечень первоочередных задач сов-

\footnotetext{
1 Электронный фонд правовых и нормативнотехнических документов http://docs.cntd.ru/document $/ 765714380$
}

нархозов, созданных в стране и непосредственно Красноярском крае.

Не исключено, что для решения возникшей управленческой проблемы в 1962 г. при Совете Министров РСФСР был создан Отдел экономического и культурного развития народов Крайнего Севера. Однако его не удалось превратить в эффективную организацию, стоявшую на страже интересов коренного населения. Ю. Слезкин утверждал, что отдел не имел специалистов, необходимых для организации систематической работы, не имел необходимых финансовых ресурсов и за короткий срок существования не сумел выработать приемлемой для новых условий хозяйствования национальной политики (Slezkin, 2008:213).

Возврат к проектам развития Крайнего Севера и решения проблем его коренных малочисленных народов был фактически сдвинут на вторую половину $60-$-х гг. XX в., когда был восстановлен отраслевой принцип управления народным хозяйством страны и провозглашен курс на ускоренное развитие производительных сил восточных районов СССР.

В этот период предпринимались активные действия по изучению и вовлечению в хозяйственный оборот гидроэнергетических ресурсов, месторождений полезных ископаемых, нефти и газа, пушных и рыбных запасов северных территорий Красноярского края ${ }^{2}$. На рубеже 60-х - 70-х гг. дальнейшее развитие получили Норильский горно-металлургический, Игарский лесоперерабатывающий комбинаты, строились Усть-Хантайская ГЭС и газопровод Мессояха - Норильск. Совершенствовалась транспортная структура региона, в которую входили: заполярная железная дорога Дудинка - Норильск - Талнах, морские порты Дудинка, Хатанга, Игарка, Диксон, аэропорты Алыкель, Хатанга, Игарка, Туруханск, Тура и Байкит.

Сложившаяся к тому времени хозяйственная специализация населения Таймырского (Долгано-Ненецкого) и Эвенкийского национального округов на пушном промысле, клеточном звероводстве и оле-

\footnotetext{
2 ГАКК. Ф.Р. 1478, оп. 3, д. 1220, л. 131
} 
неводстве давала возможность сочетать интересы государства и коренного населения округов. Расположенные там колхозы и совхозы имели оленеводческопромысловый характер, и их удельный вес в товарной продукции сельского хозяйства округов превышал $90 \% 3$.

В годы девятой пятилетки (19711975 гг.) в народное хозяйство Эвенкийского национального округа было направлено около 26 млн руб. капитальных вложений, благодаря чему объем реализации продукции промыслового и сельского хозяйства в округе увеличился на 26,5 \%, а объем заготовок пушнины вырос на 29,8 \% ${ }^{4}$.

Вложение государством в народное хозяйство Таймырского национального округа 56,3 млн руб. дало возможность округу на 38,4 \% увеличить объем заготовки пушнины и на 61,6 \% объем реализованной продукции 5 . Поддержка государством оленеводства позволила к 1977 г. довести поголовье домашних оленей в национальных округах до 124 тыс. голов ${ }^{6}$.

Расширение налогооблагаемой базы национальных округов дало значительные средства, которые направлялись на решение экономических, социальных и культурных проблем северного населения. В рассматриваемые годы удалось добиться перехода значительной части коренного населения национальных округов на оседлый образ жизни. Число лиц, имеющих высшее или специальное среднее образование, по сравнению с предыдущей пятилеткой возросло с 205 до 600 человек 7 .

Несмотря на высокое значение клеточного звероводства, оленеводства и промысловой деятельности для экономики Таймырского (Долгано-Ненецкого) и Эвенкийского национального округов, они являлись убыточными из-за особенностей ценообразования ${ }^{8}$. При затратах1692 тыс. руб. на добычу рыбы в 1975 г. ее реализация позволила получить только 1312 тыс. руб. при-

\footnotetext{
ГАКК. Ф.Р. 1478, оп. 3, д. 1219, л. 29

ГАКК. Ф.Р. 1478, оп. 3, д. 1220, л. 115

ГАКК. Ф.Р. 1478, оп. 3, д. 1220 , л. 115

6 ГАКК. Ф.Р. 1478, оп. 3, д. 1220, л. 116

ГАКК. Ф.Р. 1478, оп. 3, д. 1220, л. 116

8 ГАКК. Ф.Р. 1478 , оп. 3, д. 1219, л. 29
}

были. Затраты на производство продукции звероводства составили 938 тыс. руб. и почти в два раза превысили доход от отрасли, который равнялся 555 тыс. руб. . . Даже относительно дешевая рабочая сила не снижала убыточности промысловых хозяйств.

При этом традиционные отрасли хозяйственной деятельности Енисейского Севера по степени развития уступали хозяйствам центральной и южной частей Красноярского края. Внедрение механизации здесь сдерживалось отсутствием развитой базы ГСМ, нехваткой грузовых автомашин и тракторов, способных работать в условиях Крайнего Севера. Совхозам приходилось брать на себя расходы за доставку нефтепродуктов из Красноярска по Енисею или Северным морским путем через Мурманск и Архангельск. При цене на дизельное топливо от 40 до 80 руб. за 1 т они тратили на ее транспортировку от 120 до 360 руб.. ${ }^{10}$ В условиях сезонного характера морской и речной навигации совхозы вынуждены были создавать у себя специальные хранилища ГСМ и сокращать время использования техники на механизированных работах.

Медленными темпами развивались и другие отрасли хозяйства региона. Низкие темпы роста лесозаготовок были связаны с невысокой продуктивностью северной тайги, слабой материально-технической базой леспромхозов, отсутствием жилья для их работников ${ }^{11}$.

Государство в условиях высоких затрат на развитие производительных сил страны, поддержание еe обороноспособности не могло позволить себе безлимитное выделение финансовых средств на экономическое и социальное развитие национальных районов. Низкие цены на труд также не могли способствовать повышению уровня жизни коренного населения, которое в среднем получало за 1 ц оленеводческой продукции всего 53-73 руб. ${ }^{12}$.

Беспокойство вызывало то, что наряду с некоторыми положительными результа-

\footnotetext{
9 ГАКК. Ф.Р. 1478 , оп. 3, д. 1219 , л. 29

${ }^{10}$ ГАКК. Ф.Р. 1478 , оп. 3, д. 1219 , л. 30

${ }^{11}$ ГАКК. Ф.Р. 1478, оп. 3, д. 1219, л. 11

${ }^{12}$ ГАКК. Ф.Р. 1478, оп. 3, д. 1219, л. 11
} 
тами в экономическом развитии национальных округов нарастали проблемы, связанные с ускоренной перестройкой жизни коренного населения округов на модель, характерную для большей части территории страны.

Жилой фонд северных поселков, где проживали 94 \% коренного населения Таймырского национального округа, состоял из деревянных домов без централизованного отопления, водоснабжения и канализации, строительство которых в условиях вечной мерзлоты по стоимости многократно превышало затраты, необходимые в более комфортных природно-климатических условиях ${ }^{13}$

Проблемой региона оставалось производственное и жилищное строительство, которое осуществлялось по проектам, адаптированным к северным условиям, но не имело специальных строительных материалов, необходимых для строительства в северных условия ${ }^{14}$. Для северных территорий не всегда подходила продаваемая в магазинах бытовая техника.

В крупных населенных пунктах Таймырского и Эвенкийского национальных округов велось строительство телевизионных станций и начиналась трансляция не только радио, но и телевизионных передач, но большой проблемой для северных территорий оставалась телефонная связь, которой за исключением окружных и районных центров не было оборудовано большинство населенных пунктов вышеназванных округов и Туруханского района $^{15}$.

Оставалась крайне слабой материально-техническая база учреждений здравоохранения, образования и культуры, многие из которых находились в неприспособленных зданиях первой половины века с износом 70-90 \%. Эти учреждения испытывали нехватку необходимых кадров ${ }^{16}$.

Для решения кадровой проблемы государство выделяло в учебных заве-

\footnotetext{
${ }^{13}$ ГАКК. Ф.Р. 1478 , оп. 3, д. 1218, л. 204

${ }^{14}$ ГАКК. Ф.Р. 1478 , оп. 3, д. 1218 , л. 12, 13

15 ГАКК. Ф.Р. 1478, оп. 3, д. 1220 , л. 14

${ }^{16}$ ГАКК. Ф.Р. 1478 , оп. 3, д. 1220 , л. 18, 21
}

дениях среднего и высшего образования места для молодежи из коренного населения ${ }^{17}$.

Но кадровая ситуация осложнялась тем, что обучение детей в интернатах в отрыве от семей зачастую сопровождалось маргинализацией части подрастающего поколения, которое утрачивало интерес к традиционному образу жизни и хозяйственной деятельности. Многие выпускники специальных учебных заведений предпочитали оставаться в местах обучения. И, как показала практика, коренное население в силу определенных причин больше доверяло русским врачам, чем своим соотечественникам.

Перестройка питания коренного населения в соответствии с существующими в стране нормами питания привела к продовольственной зависимости северных округов от поставок с «материка» в период «северного завоза». Они самостоятельно могли обеспечить себя такой продукцией нетрадиционного питания, как молоко, только на $12 \%$, овощами и яйцом всего на $3 \%{ }^{18}$.

Уровень потребления жителей Таймырского и Эвенкийского национальных округов значительно отставал от норм, установленных Институтом питания Академии медицинских наук СССР. Местное население потребляло меньше чем в среднем по Красноярскому краю: мяса в 3 раза, молока в 6,7 раза, картофеля в 11,9 раза, овощей в 7,8 раз ${ }^{19}$. Бесспорно, возникает вопрос о причинах нехватки мяса в условиях регистрируемого специалистами роста поголовья домашних оленей и стада диких оленей, численность которого приближалась к миллиону голов.

Необходимость дальнейшего развития хозяйственного комплекса северных территорий края и решения накопившихся социальных проблем потребовала разработки нового комплексного проекта их развития. Госплан РСФСР ставил задачу доведения социального, экономического и культурно-

\footnotetext{
${ }^{17}$ ГАКК. Ф.Р. 1478, оп. 3, д. 1220, л. 18, 21

${ }^{18}$ ГАКК. Ф.Р. 1478, оп. 3, д. 1221, л. 204

19 ГАКК. Ф.Р. 1478 , оп. 3, д. 1220 , л. 3
} 
го развития этих народов до уровня титульной нации РСФСР 20.

Органы государственного управления, опираясь на свой опыт и опыт США, Канады и северных европейских стран, осознавали, что в условиях малочисленности, крайней рассредоточенности и при этническом разнообразии местных народов их будет невозможно в массовом порядке привлечь к промышленным видам деятельности. Люди, привыкшие жить в соответствии с природными циклами, тяжело и с большими издержками адаптировались к индустриальному труду.

Госплан СССР 9 декабря 1976 г. поручил краевой плановой комиссии Красноярского края разработать план развития территорий Крайнего Севера Красноярского края на период X-XII пятилеток (1977-1990 гг.)21. Была поставлена задача постепенной перестройки сельского и промыслового хозяйства северных территорий на индустриальный уровень. В Красноярском крае была создана специальная комиссия, в которую вошли заместитель председателя крайисполкома Красноярского края Ю. А. Нарушкин, заведующий отделом по народностям Севера крайисполкома И. С. Савченко, заместитель председателя краевой плановой комиссии В. А. Дубовец, генеральный директор объединения «Красноярскрыбпром» В.К. Миргунов, начальник управления гражданской авиации А.Т. Жалина, председатели Таймырского окрисполкома Т.С. Еремин, Эвенкийского - В.Г. Суевалов и Туруханского райисполкома Н. А. Захаринский.

При знакомстве с планом, составленным комиссией, очевидным является его сходство с постановлением ЦК КПСС и Совета министров СССР № 300, принятым в 1957 г.

Первое, что бросается в глаза при анализе состава комиссии, отвечавшей за план культурного и экономического развития народов Крайнего Севера Красноярского края, - это отсутствие в ней представителей этих народов. Конечно же, работе самой комиссии предшествовали обсуждения

\footnotetext{
${ }^{20}$ ГАКК. Ф.Р. 1478 , оп. 3 , д. 1220 , л. 3

21 ГАКК. Ф.Р. 1478, оп. 3 , д. 1220, л. 3
}

проектов, созданных в рамках плановых отделов Таймырского, Эвенкийского окрисполкомов и Туруханского райисполкома, но доля коренного населения в их составе была незначительной.

Одной из центральных задач плана являлся дальнейший перевод коренных народов Севера на оседлый образ жизни. Одним из главных путей достижения этой цели, по мнению органов управления Красноярского края и РСФСР, было повышение уровня дохода и качества жизни народов Крайнего Севера в рамках сельскохозяйственных предприятий. Перед Советами министров автономных республик, крайисполкомами, облисполкомами, Минсельхозом, Минмясопромом, Главохотой, Минрыбхозом РСФСР и Роспотребсоюзом ставилась задача обеспечить на севере развитие всех отраслей сельского хозяйства: рыбной, пушной, зверобойной промышленности, сбора дикоросов, производства мяса, молока, яиц, картофеля и др. ${ }^{22}$.

В выполнении Плана развития территорий Крайнего Севера на 1977-1990 гг. преобладала роль министерств сельского хозяйства, рыбной промышленности, в системе которых работало большинство населения северных округов. Авиация выступала единственным круглогодичным средством связи и перемещения населения, продукции и товаров между Севером и «материком».

В плане были представлены и другие министерства и ведомства РСФСР. Но в отличие от министерств сельского хозяйства и рыбной промышленности они отвечали за развитие отраслей союзного и республиканского значения, на которые местные органы управления не имели непосредственного влияния.

Так как основной целью Плана декларировалось ускоренное социальноэкономическое и культурное развитие коренных народов Сибири, выравнивание уровня их жизни с уровнем жизни основной массы населения страны, то были приняты меры по увеличению выделения финансовых средств на развитие народно-

\footnotetext{
${ }_{22}^{22}$ ГАКК. Ф.Р. 1478 , оп. 3, д. 1220, л. 126-129
} 
Таблица 1. Сопоставительная таблица по развитию сельскохозяйственного производства районов Севера Красноярского края

Table 1. Comparative table on the development of agricultural production in the Northern districts of Krasnoyarsk Krai

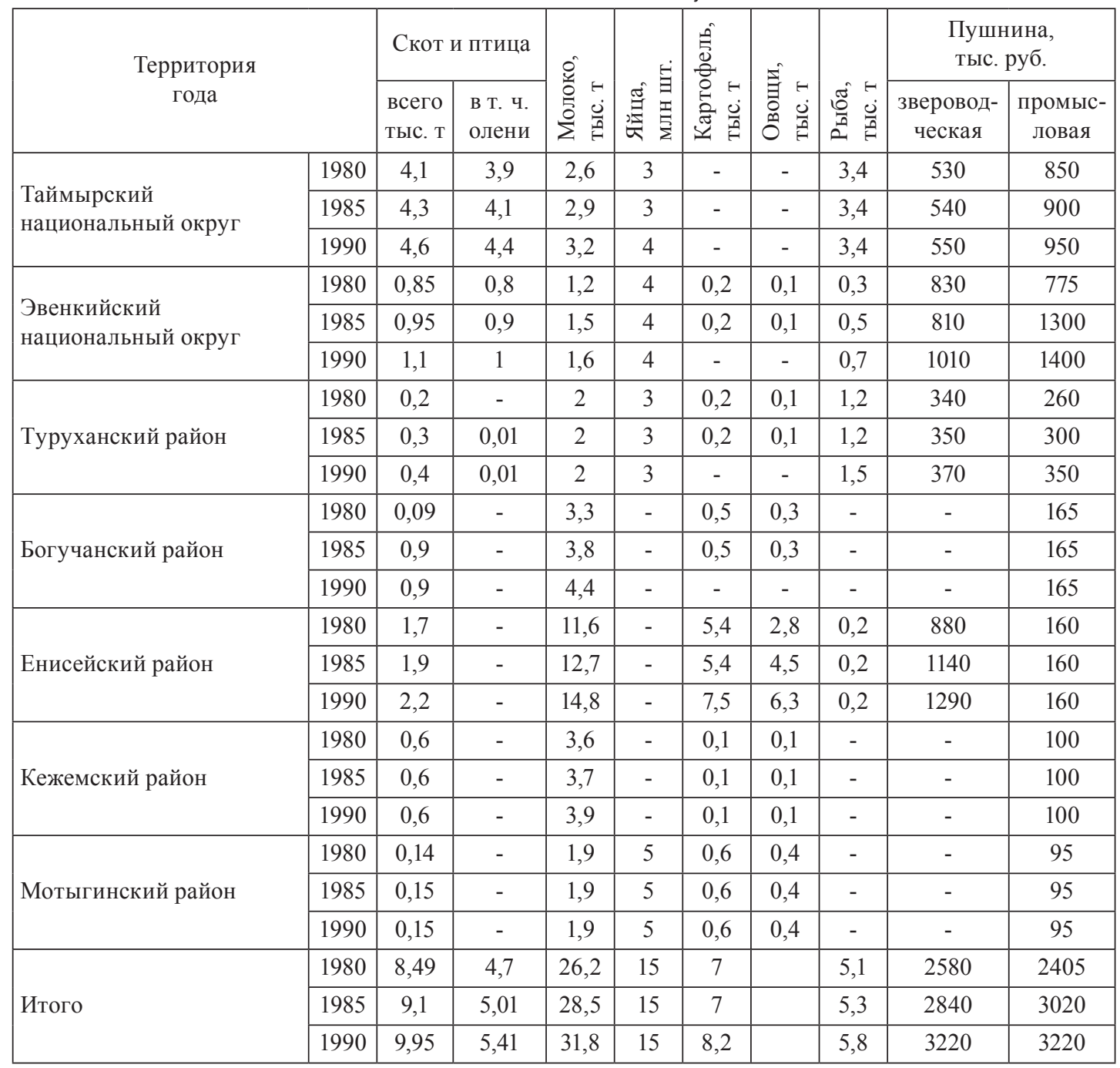

На основе данных ГАКК. Ф.Р. 1478, оп. 3, д.1215, 1216, 1219, 1220, 1221, 1222.

хозяйственного комплекса северных территорий. Можно видеть составленную нами таблицу заданий по производству сельскохозяйственной продукции районов Севера (табл. 1).

В целом, как видно из данных табл. 1, план предполагал достаточно стабильное развитие отраслей. В более отдаленной перспективе планировалась даже организация в Эвенкийском округе на основе последних достижений науки и техники коровников на тысячу голов скота. Одним из центральных элементов плана было исправление закупочных цен на продукцию совхозов и колхозов районов Крайнего Севера. Госкомитету цен было поручено повысить закупочные цены на большинство видов пушной продукции, приравнять цены на мясо диких копытных к цене мяса домашнего скота, цену рыбы сырца частиковых по- 
род - к закупочным ценам сиговых пород, снять ряд ограничений в области лова 23.

Одновременно с этим предполагалось повысить материальную заинтересованность хозяйств и работников, занятых в основных отраслях хозяйства народностей Севера, путем увеличения заработной платы, развития системы премирования, в том числе введения надбавок за производство сверхплановой продукции, предполагалось более широкое использование хозрасчетных отношений ${ }^{24}$.

В целях развития торговли было поручено освободить Крайрыбпотребсоюз на 15 лет от уплаты в бюджет подоходного налога с прибыли и направить эти средства на развитие материально-технической базы торговли и заготовки ${ }^{25}$. Одновременно предполагалось ввести скидку на завозимые плановые промтовары в среднем на $10 \%$.

${ }^{23}$ ГАКК. Ф.Р. 1478, оп. 3, д. 1220, л. 117-119

${ }^{24}$ ГАКК. Ф.Р. 1478 , оп. 3, д. 1220 , л. 127

${ }^{25}$ ГАКК. Ф.Р. 1478, оп. 3, д. 1220 , л. 120
Госстрою СССР было поручено разработать и утвердить новые нормативные проекты и документы для жилых домов и публичных учреждений и производственных зданий для территорий Крайнего Сeвера. При этом предполагалось ограничить использование деревянного строительства жилых домов, производственных зданий и промышленных объектов ${ }^{26}$. Планировалось обеспечить развитие авиационного и речного транспорта.

В целях развития образования планировалось освободить коренное население от уплаты за обучение детей в музыкальных, художественных, хореографических школах. Планировалось развернуть массовое строительство новых учебных заведений, больниц и объектов культуры.

Примечательно, что заказчиками тех или иных проектов чаще являлись конкретные хозяйственные министерства и главки, чем местные советы (табл. 2).

${ }^{26}$ ГАКК. Ф.Р. 1478 , оп. 3, д. 1220 , л. 118

Таблица 2. План строительства объектов здравоохранения, просвещения и культуры в районах Крайнего Севера Красноярского края на 1977-1990 гг.

Table 2. Plan of construction of health care, education and cultural facilities in the Far North of Krasnoyarsk Krai for 1977-1990

\begin{tabular}{|c|c|c|}
\hline Территория & Объект & Заказчик \\
\hline 1 & 2 & 3 \\
\hline \multirow{14}{*}{$\begin{array}{l}\text { Таймырский } \\
\text { национальный округ }\end{array}$} & Терапевтический корпус в г. Дудинке & Минцветмет \\
\hline & Роддом в г. Дудинке & Местные советы \\
\hline & Больница в пос. Хатанга & Мингео \\
\hline & $\begin{array}{l}\text { Окружной противотуберкулезный } \\
\text { диспансер в г. Дудинке }\end{array}$ & Местные советы \\
\hline & Поликлиника в г. Дудинке & Минцветмет \\
\hline & Школа в г. Дудинке & Минцветмет \\
\hline & Школа в пос. Хатанга & Местные советы \\
\hline & Школа в пос. Хета & Минсельхоз \\
\hline & Школа в с. Сындасско & Минсельхоз \\
\hline & Школа в пос. Кресты & Минсельхоз \\
\hline & Школа в с. Новорыбное & Местные советы \\
\hline & Школа в пос. Диксон & Местные советы \\
\hline & Школа в пос. Носок & Местные советы \\
\hline & Школа в пос. Новая & Минсельхоз \\
\hline
\end{tabular}


Продолжение табл. 2

Continued Table 2

\begin{tabular}{|c|c|c|}
\hline 1 & 2 & 3 \\
\hline \multirow{6}{*}{$\begin{array}{l}\text { Таймырский } \\
\text { национальный округ }\end{array}$} & Клуб в пос. Усть-Авам & Главохота \\
\hline & Клуб в с. Волочанка & Минсельхоз \\
\hline & РДК в с. Хатанга & Местные советы \\
\hline & Клуб в пос. Жданиха & Минсельхоз \\
\hline & Клуб в пос. Новая & Минсельхоз \\
\hline & Библиотека в РДК с. Хатанга & Местные Советы \\
\hline \multirow{16}{*}{$\begin{array}{l}\text { Эвенкийский } \\
\text { национальный округ }\end{array}$} & Терапевтический корпус в пос. Байкит & Мингео \\
\hline & Окружная больница в р. п. Тура & Местные советы \\
\hline & Терапевтический корпус в пос. Ванавара & Местные советы \\
\hline & Поликлиника в р. п. Тура & Минцветмет \\
\hline & Школа в пос. Байкит & Мингео \\
\hline & Школа в пос. Тура & Местные советы \\
\hline & Школа в с. Ессей & Минсельхоз \\
\hline & Школа в с. Тутончаны & Минпромстрой-материалов \\
\hline & Школа в Ногинске & Минпромстрой-материалов \\
\hline & Клуб в пос. Эконда & Минсельхоз \\
\hline & Клуб в пос. Чиринда & Минсельхоз \\
\hline & Клуб в пос. Тутончаны & Минсельхоз \\
\hline & РДК в р. п. Тура & Местные советы \\
\hline & Клуб в с. Байкит & Мингео \\
\hline & Клуб в пос. Ессей & Минсельхоз \\
\hline & Библиотека в РДК р. п. Тура & Местные Советы \\
\hline \multirow[t]{16}{*}{ Туруханский район } & Больница в пос. Зотино & Минлеспром \\
\hline & Больница в пос. Бор & Мингео \\
\hline & Больница в пос. Туруханск & Местные советы \\
\hline & Поликлиника в пос. Туруханск & Местные советы \\
\hline & Школа в пос. Туруханск & Местные советы \\
\hline & Школа в пос. Верещагино & Минлеспром \\
\hline & Школа в пос. Бор & Мингео \\
\hline & Школа в пос. Бор & МГА \\
\hline & Школа в пос. Селиваниха & Минсельхоз \\
\hline & РДК в с. Туруханск & Местные советы \\
\hline & Клуб в пос. Зотино & Минлеспром \\
\hline & Клуб в с. Ворогово & Минлеспром \\
\hline & Клуб в пос. Фарково & Главохота \\
\hline & Клуб в пос. Кеалог & Главохота \\
\hline & Клуб в пос. Советская речка & Главохота \\
\hline & Библиотека в РДК с. Туруханск & Местные советы \\
\hline
\end{tabular}

Составлено по ГАКК. Ф.Р. 1478, оп. 3, д.1215. 


\section{Заключение}

Созданный в конце 1970-х гг. план развития территорий Крайнего Севера Красноярского края был результатом государственной стратегии развития восточных районов страны и непосредственно ее северных территорий. Рост доли продажи природных ресурсов на мировом рынке повлиял на ускорение развития северных территорий. Новый план хоть и выглядел частичным повторением тех идей, что были сформулированы за двадцать лет до этого, тем не менее он предполагал значительную работу по повышению уровня жизни местного населения. В его основе лежали принципы плановости и ведомственности. Он был воплощением хозяйственных принципов советской системы управления. Другое дело, что судьба этого плана повторила судьбу указа № 300. Его пытались выполнять, но в условиях «перестройки» вновь был ликвидирован механизм осуществления, заложенный в его основу. Лишь отдельные его элементы воплощены в жизнь. Сегодня правительство снова ищет пути развития северных территорий Красноярского края, повторяя отдельные идеи того, что было прежде.

\section{Список литературы / References}

Dvoretskaya A.P. (2021). Hozyajstvennyj uklad russkih starozhilov Turuhanskogo kraya (vtoraya polovina XIX-nachalo XX) [The economic structure of the Russian old-timers of the Turukhansk region (second half of the 19th - early 20th centuries)] In Grishaevskie ctenya, 177-183.

Dvoretskaya A.P., Sedelnikov, V.G. (2020). Po sledam ekspedicii Ruala Amundsena na shkhune «Mod»: formirovanie mest pamyati [Following the Roald Amundsen's expedition by the schooner «Mod»: organization of memorial places] In Balandinskie chteniya, 15, 323-332. Doi: 10.24411/9999-001A-202010037.

Gololobov E. I. (2017) Sibirskij sever: dinamia obraza- ot barren grounds k northern plain [The Siberian north and the dynamics of image: to barren grounds for northern plain] In QUAESTIO ROSSICA, 1, 137-152. DOI: 10.15826/qr.2017.1.216.

Mikhheeva Y.S. (2017) Konstruirovanie obraza prirody sibirskogo evera v regionalnoy pechati 19501980s. [Constructing the image of the nature of the Siberian North in the regional press of the 1950s and 1980s.], In Vestnik surgutskogo gosudarstvennogo pedagogicheskogo universiteta, 6(51), 55-60.

Veselov S. I. (2017) Sozdanie localnoj avtodorozhnoj seti v neftedobyvayushcih rajonah severa zapadnoj Sibiri v seredine 1960-h-1970s [Establishment of the local autodiversity in the non-feeding areas of the North of Western Siberia in the 1960s-1970s], in Istoricheskie, filosofskie, politicheskie I yurodocheskie nauki, kulturologia I uskusstbobedenie. Voprosi teorii I (Historical, philosophical, political and legal sciences, culturology and art history. Theory and practice issues), 44-48.

Hobsbawm E. (2004) Epoha krajnostej: Korotkij dvadcatyj vek (1914-1991) [Epoch of extremes: the Twentieth Century]. M.: Izdatel'stvo Nezavisimaya Gazeta, 632 p.

Turaev V.A.(2014) Korennye narody Dal'nego Vostoka kak ob»ekt ideologicheskoj manipulyacii i ekonomicheskij resurs in Sovetskij Dal'nij Vostok v stalinskuyu i poststalinskuyu epohu [The Root Peoples of the Far East as an Object of Ideological Manipulation and Economic Resource in the Soviet Far East in the Stalinist and Post-Stalinist Epoch Establishment of the local autodiversity in the non-feeding areas of the North of Western Siberia in the 1960s-1970s]. 132-138.

Slezkin Y.U. (2008) Arkticheskie zerkala: Rossiya i malye narody Severa [Arctic mirrors: Russia and the small peoples of the North]. NLO, 2008, 512 p.

Stas I.N. (2017) Drejf etnichnosti v processe neftegazovogo osvoeniya I urbanizachii HantyMasijslogo okruga (1960-1980s.) [Ethnicity drift in the process of oil and gas development and urbanisation in Khanty-Mansiysk] in Vestnik Tomskogo gosudarstvennogo universiteta. 414. p. 134-140. DOI: $10.17223 / 15617793 / 414 / 21$ 